\title{
HCV Antigen Therapeutic Bivalent Vaccine V5
}

National Cancer Institute

\section{Source}

National Cancer Institute. HCV Antigen Therapeutic Bivalent Vaccine V5. NCI Thesaurus.

Code C118361.

An orally bioavailable, therapeutic bivalent vaccine composed of heat- and chemicalinactivated hepatitis $\mathrm{C}$ virus (HCV) antigens derived from the blood of HCV-infected carriers, with potential immunomodulating activity. Upon oral administration of the HCV antigen therapeutic bivalent vaccine V5, the HCV antigens may stimulate the host immune system to mount an immune response against HCV-infected cells, thereby preventing further HCV-infection and HCV-induced liver injury. 